evidence for programme content, evidence is less on the optimum duration or comparative efficacy in different settings.

Two English NHS pulmonary rehabilitation services used different service models for COPD patients. An acute based service offered up to nine weekly sessions of pulmonary rehabilitation using a multi-disciplinary team. Another service based in a community gym offered up to ten sessions provided by respiratory nurses and a physical activity co-ordinator.

We hypothesised that outcomes would not improve after eight pulmonary rehabilitation sessions and would be similar for the two services.

Methods A pragmatic service evaluation with before-after design was used. Self-reported chronic respiratory questionnaires (CRQ) measuring four quality of life domains (dyspnoea, fatigue, emotional function, mastery) were completed by patients at baseline and again on completion of pulmonary rehabilitation. For each service, baseline scores were subtracted from completion scores to measure change in respiratory related quality of life outcomes and compared to minimum clinically important difference (MICD) of 0.5 (Williams et al, 2003).

The effect of number of sessions attended by patients on respiratory outcome scores was tested using linear regression.

Results Baseline and follow-up CRQ scores were available for 149 patients (89 in the acute based service).

In the community based service, improvements in dyspnoea and emotion were statistically significantly greater than the MCID whereas for the acute service, improvements in emotional function and mastery were significantly greater than MCID (Table 1). The overall proportion of patients experiencing CRQ increases greater than the MCID for both services were dyspnoea: $62.4 \%$; fatigue: $57.7 \%$; emotional function: $61.7 \%$; mastery: $59.1 \%$ at follow up.

The effect of duration on CRQ outcomes will be reported. Conclusions A community based pulmonary rehabilitation service obtained similar CRQ outcomes to an acute based service suggesting community based services may achieve equally good outcomes to acute based services.

\begin{tabular}{|c|c|c|c|c|c|c|}
\hline Service & $\begin{array}{l}\text { CRQ } \\
\text { Dimension }\end{array}$ & $\begin{array}{l}\text { Mean } \\
\text { pre- score }\end{array}$ & $\begin{array}{l}\text { Mean } \\
\text { post- score }\end{array}$ & Difference & $\begin{array}{l}95 \% \\
\mathrm{Cl}\end{array}$ & $\begin{array}{l}\text { Proportion } \\
>\text { MCID (\%) }\end{array}$ \\
\hline \multirow[t]{4}{*}{ Community } & y Dyspnoea & 2.48 & 3.51 & 1.03 & 0.661 .40 & 63.3 \\
\hline & Fatigue & 3.23 & 4.05 & 0.82 & 0.471 .17 & 51.7 \\
\hline & Emotion & 3.88 & 4.79 & 0.91 & 0.591 .24 & 61.7 \\
\hline & Mastery & 4.06 & 4.74 & 0.68 & 0.291 .07 & 55.0 \\
\hline \multirow[t]{4}{*}{ Acute } & Dyspnoea & 2.79 & 3.61 & 0.83 & 0.601 .06 & 61.8 \\
\hline & Fatigue & 3.07 & 3.89 & 0.82 & 0.601 .03 & 56.2 \\
\hline & Emotion & 4.03 & 4.60 & 0.57 & 0.380 .77 & 51.7 \\
\hline & Mastery & 4.19 & 4.85 & 0.65 & 0.420 .88 & 50.6 \\
\hline
\end{tabular}

Minimum clinically important difference (MCID) (Williams EA, S J Singh, L Sewell, M D L Morgan. Health status measurement: sensitivity of the self-reported Chronic Respiratory Questionnaire (CRQ-SR) in pulmonary rehabilitation. Thorax 2003;58:515-518)

\section{P118 POST DISCHARGE PULMONARY REHABILITATION FOR ACUTE EXACERBATION COPD DOES NOT ALWAYS REDUCE RE-ADMISSION RATES}

${ }^{1} \mathrm{SE}$ Roberts, ${ }^{1} \mathrm{~N}$ Kodumooru, ${ }^{2} \mathrm{~S}$ Purcell, ${ }^{2} \mathrm{~A}$ Williamson, ${ }^{2} \mathrm{H}$ Broomfield, ${ }^{3} \mathrm{U}$ Restrick, ${ }^{3} \mathrm{M}$ Stern; 'Whittington Hospital Physiotherapy, Whittington Health, London, UK;
${ }^{2}$ Community Respiratory Team, Whittington Health, London, UK; ${ }^{3}$ Dept Respiratory Medicine, Whittington Health, London, UK

\subsection{6/thoraxjnl-2013-204457.268}

Introduction Post-discharge pulmonary rehabilitation (PR) within 7-10 days after discharge from hospital admission for acute exacerbation of COPD (AECOPD) has been shown not only to result in the well-described benefits of PR (reduced breathlessness, improved exercise performance and health-related quality of life), but also to reduce emergency department attendances over a 3 month period. We report the outcomes of a locally-provided post-exacerbation PR (PEPR) pilot study for patients admitted to hospital with AECOPD, and compares outcomes and subsequent 90-day re-admission rates with published RCT data showing re-admission reduction from 33 to $7 \%{ }^{1}$.

Methods Patients were recruited during AECOPD admission to start PR within 10 days of discharge from hospital. Taxi transport was offered to all patients. Outcome measures chosen were change in: 6-Minute Walking Test (6MWT), Hospital Anxiety and Depression Score (HADS), Chronic Respiratory Disease Questionnaire (CRDQ), and 90-day re-admission rates.

Results 43 patients were offered PEPR, 32 started and 21/32 (66\% of starters, $49 \%$ of all referrals) completed the course (>11/16 sessions). Mean (range) age was 67(40-86) years and mean (SD) \%predicted $\mathrm{FEV}_{1}$ 32(15)\%. Median time (range) between discharge from hospital and starting PEPR was $8(0-17)$ days. There were clinically significant improvements in $6 \mathrm{MWT}$ median (range) $27 \%(-40-+233)$ and CRDQ dyspnoea domain $0.79(-0.60-+3.00)$. There was no clear effect on 90-day readmission rate: $45 \%$ patients who started PEPR were re-admitted v 58\% who were offered but declined PEPR. Local 90-day re-admission rate for all 2012 AECOPD admissions was 39\%.

Conclusion This study failedto replicate published reductions in re-admission rates in a patient population that was more severe than the comparison study, mean\%predicted $\mathrm{FEV}_{1} 32 \%$ v $52 \%{ }^{1}$. Value of PEPR programmes in reducing AECOPD re-admission rates needs further investigation across disease severity spectrum. An additional area that would benefit from further investigation is completion rate for $\mathrm{PEPR}^{2}$; completion rate from referral for PEPR at $49 \%$ compares to $43 \%$ for our standard PR programme.

\section{REFERENCES}

1. Seymour et al. Outpatient pulmonary rehabilitation following acute exacerbations of COPD. Thorax 2010:65:423-428

2. National Institute of Health Research, HTA no 13/24 'does starting PR early following AECOPD improve adherence and outcomes compared to starting rehabilitation later?'

\section{P119 RESPONSIVENESS OF THE CAT (COPD ASSESSMENT TOOL) IN A STABLE AND POST EXACERBATION PULMONARY REHABILITATION POPULATION}

${ }^{1}$ EJL Chaplin, ${ }^{2} E J L$ Chaplin, 'M Gibb, 'L Sewell, 'S Singh, ${ }^{3} S$ Singh; 'Pulmonary Rehabilitation Department, Glenfield Hospital, University Hospitals of Leicester NHS Trust, Leicester, UK; ${ }^{2}$ Centre for Exercise and Rehabilitation Science, NIHR Leicester Respiratory BRU, UHL NHS Trust, Leicester, UK; ${ }^{3}$ Faculty of Health and Life Sciences, Coventry University, Coventry, UK

\subsection{6/thoraxjn-2013-204457.269}

Introduction The CAT is an eight item questionnaire used to assess health status. It has previously been used in stable COPD and non COPD patients (Kon et al, 2012) and as an outcome measure for pulmonary rehabilitation (PR) in the short term in a 